Научная статья

УДК 334

DOI 10.18101/2304-4446-2021-4-62-69

\title{
ОСОБЕННОСТИ ХОЗЯЙСТВОВАНИЯ ИННОВАЦИОННЫХ БИЗНЕС-СТРУКТУР В ПРОМЫШЛЕННОЙ ЭКОНОМИКЕ СОВМЕСТНОГО ПОТРЕБЛЕНИЯ
}

\author{
(C) Жаринов Игорь Олегович \\ доктор технических наук, профессор, \\ Национальный исследовательский университет ИТМО \\ Россия, 197101, г. Санкт-Петербург, Кронверкский проспект, 49А \\ mpbva@mail.ru,
}

\begin{abstract}
Аннотация. Совместное потребление является экономической моделью отношений бизнес-структур и потребительского сообщества, в которой владение активом замещается на его возмездную аренду коллективным пользователем. В статье рассматриваются особенности хозяйствования инновационных бизнес-структур, классифицируемых как субъекты экономических отношений - кластеры Индустрии 3.0+ и бизнессистемы Индустрии 4.0, реализующие модель совместного потребления промышленных активов. Приводится анализ институциональных условий экономики совместного потребления как факторов развития отечественной промышленности и предлагаются стратегии экономического роста хозяйствующих субъектов, связанные с шерингом киберфизического производственного оборудования, а также анализ экономических рисков, обусловленных технологической сингулярностью промышленности, вызванной оперативной цифровизацией производственной среды и возросшей ролью искусственного интеллекта в бизнес-процессах. Формирование и развитие инновационных бизнес-структур для экономики совместного потребления рассмотрены в аспектах трансформации рынка труда.
\end{abstract}

Ключевые слова: экономика совместного потребления, Индустрия 4.0, шеринг киберфизических систем, технологическая сингулярность, риски.

\section{Для цитирования}

Жаринов И. О. Особенности хозяйствования инновационных бизнес-структур в промышленной экономике совместного потребления // Вестник Бурятского государственного университета. Экономика и менеджмент. 2021. № 4. С. 62-69.

\section{1 Введение}

Появление новой концепции Индустрии 4.0, отождествляемой сегодня в научной литературе с четвертой промышленной революцией, является закономерным этапом (более высокой ступенью) эволюционного развития социальноэкономических систем, рассматриваемых в приложении к экономике производства. Согласно исследованиям [1], посвященным «технологическим укладам», революционные изменения в производственном сегменте на этапах модернизации существующих и формирования, развития (стабилизации) новых хозяйствующих субъектов сами по себе не приводят к значимому экономическому эффекту. Это объясняется сложившимися стереотипами хозяйствования и высоким уровнем априорной неопределенности ожидаемых результатов внедрения в промышленную инфраструктуру инновационных технологий и передовых средств производства, однако по мере накопления, совершенствования и практического 
И. О. Жаринов. Особенности хозяйствования инновационных бизнес-структур в промышленной экономике совместного потребления

использования таковых экономический рост показателей результативности бизнеса существенно ускоряется.

Причинно-следственная связь этапов жизненного цикла «технологического уклада» и успешности производительной деятельности бизнеса обусловлена «диффузией» технологий [2] в бизнес-процессы компаний, адаптационными возможностями и способностями хозяйствующих структур к учету динамики рынка и изменений институциональных условий национальной (глобальной) экономики. В теоретическом пределе такая диффузия, объектом которой является искусственный интеллект, приводит к технологической сингулярности промышленности.

Подобно ротации трудовых коллективов, адаптивно изменяющихся под уровень квалификации большинства работников, требуемый компании, в национальной экономике сегодня образуются бизнес-системы Индустрии 4.0 и наукоемкие кластеры Индустрии 3.0+ как центры технологических компетенций. Внедрение отдельных инновационных технологий в модернизируемое производство (экономика изменений Индустрии 3.0+ [3]) в стратегическом плане эквивалентно содержанию в компании уникального по знаниям специалиста, трудовые функции которого необходимо координировать с функциями существующих среднестатистических работников в долгосрочной перспективе, что, очевидно, будет малопродуктивно (работник рано или поздно перейдет в другую компанию, имеющую техническое оснащение и компетенции персонала, соответствующие его повышенной квалификации).

В связи с этим эффективное построение инновационной бизнес-системы Индустрии 4.0 следует ожидать от радикальной трансформации промышленности, начинающейся с ее первичных звеньев, с поддерживающей государственной стратегией, основанной на создании «с нуля» цифровизированных компаний («фабрик будущего» [4]) и их агломераций, полностью сконцентрированных на кибертехнологиях в реализуемых цепочках стоимости. В Российской Федерации такие стратегии и меры на современном этапе пилотно осуществляются через институциональные условия и инструменты особых экономических зон и компаний Индустрии 3.0+ в Липецке, Томске, Санкт-Петербурге, Зеленограде, Елабуге и др., предусматривающие [5, 6]:

- бизнес-модели хозяйствования с шерингом высокотехнологичного оборудования - киберфизических систем - для коллективного доступа субъектов малого и среднего бизнеса к дорогостоящим промышленным ресурсам, востребованным при проектировании и изготовлении кастомизированной продукции;

- формат хозяйствования в виде региональных бизнес-кластеров и их дочерних бизнес-структур Индустрии 3.0+, а также инновационных территориально распределенных в мировом масштабе бизнес-систем Индустрии 4.0, обладающих потенциалом привлечения частных инвестиций и импортозамещающими продуктовыми линейками.

\section{2 Кластеры Индустрии 3.0+ vs бизнес-системы Индустрии 4.0}

Согласно формальному определению, предложенному М. Е. Porter, кластер как хозяйствующий субъект экономики на переходном этапе инфраструктурной трансформации промышленности конфигурируется из компаний, объединенных по территориально-географическому принципу и функционирующих в конкурентных условиях на основе межфирменной кооперации и межотраслевой кол- 
лаборации в зависимых производственно-сбытовых цепочках создания ценности. Необходимыми условиями формирования кластера в частности и бизнесагломераций компаний Индустрии 3.0+ в целом в соответствии с «принципами экономической науки» A. Marshall являются институт производственного наставничества; поддержка и развитие смежных производственному сегменту отраслей; совместное использование производственных мощностей и наличие локального рынка квалифицированного труда. В Российской Федерации кластерная политика регулируется «Концепцией долгосрочного социальноэкономического развития Российской Федерации на период до 2020 г.», утвержденной распоряжением Правительства РФ №1662-р от 17.11.2008.

Региональное свойство существования кластера, ориентированного исключительно на условия местного делового климата, является признаком, принципиально отличающим формируемые в настоящее время инновационные структуры (бизнес-инкубаторы, бизнес-полигоны, бизнес-кластеры) Индустрии $3.0+$ от сетевых и территориально распределенных бизнес-систем «будущего», ориентированных на цифровую экономику и Индустрию 4.0 и обладающих консолидированным бюджетом. Также в бизнес-системах Индустрии 4.0 имеет место замещение способа концентрированного вертикального управления, связанного с бизнес-отношениями цифровой, умной и виртуальной фабрик в общей цепочке ценности, основанными на собственности в пользу модели экономического управления с усиленным влиянием горизонтальных связей.

По данным исследования [7], сконцентрированного на проблемах производственного взаимодействия крупного бизнеса и компаний Индустрии $3.0+$ малого и среднего бизнеса, в период 2017-2020 гг. в Российской Федерации базовой формой межфирменной кооперации и кросс-отраслевой коллаборации в высокотехнологичном сегменте промышленности выступали бизнес-инкубаторы, организованные с государственным участием ( $47,1 \%$ бизнес-отношений). Также реализованы проекты ресурсами бизнес-акселераторов, самостоятельно учрежденных корпорациями $(29,6 \%)$ или независимыми венчурными структурами $(25,6 \%)$, роль которых существенно возросла. Так, доля финансовых средств, предоставленных $\mathrm{AO}$ «Российская венчурная компания» в обеспечение высокотехнологичных кооперационных бизнес-проектов, к 2020 г. составила 85\%, что практически в два раза превышает аналогичный показатель 2017 г. Вместе с тем бизнессистем Индустрии 4.0, к сожалению, в настоящее время в РФ так и не создано и, соответственно, отсутствует предметно-ориентированная статистика Росстата.

\section{3 Компании Индустрии 4.0 в шеринговой экономике}

Перевод промышленности на кибертехнологии и внедрение принципов шеринговой экономики в регулирование отношений бизнеса и потребительского сообщества создают основу для возникновения новых экономических закономерностей и явлений, присущих сегменту производства продукции или услуги. Пример нарушения устоявшихся экономических причинно-следственных связей представлен, в частности, в [1], в которой показаны прямые зависимости повышения объемов ресурсов, расходуемых на производство единицы продукции, и ее калькулируемой цены в компаниях Индустрии 3.0 и обратные зависимости (с увеличением объемов накопленных баз данных, используемых искусственным интеллектом, цена на конечную продукцию падает) в компаниях Индустрии 4.0. 
И. О. Жаринов. Особенности хозяйствования инновационных бизнес-структур в промышленной экономике совместного потребления

Эволюция бизнес-моделей промышленных компаний составила предмет исследований [8], согласно которым основными фазами бизнеса являются рост, ограничение роста, сокращение роста, сохранение преимуществ, последовательно сменяющие друг друга в результате научно-технического прогресса и «созревания» технологий, а также возникновения новых типов экономических отношений между хозяйствующими субъектами. Специалистами исследовательской компании Gartner (США) также выявлены определенные циклические закономерности (кривая Gartner) в процессах результативности бизнеса, связанные с промышленным освоением инновационных технологий и сопутствующими затратами, ожиданиями менеджмента и реальным вкладом технологий в цепочки стоимости.

Применительно к инфраструктурным и институциональным условиям экономики совместного потребления (изменению текущей парадигмы потребления на шеринг) менеджмент инновационной бизнес-системы Индустрии 4.0 для усиления рыночных позиций «фабрик будущего» может рассматривать несколько бизнес-стратегий экономического развития хозяйствующего объекта, требующих различных управленческих решений:

- исключающее продажу - предоставление в шеринг киберфизических систем, не загруженных собственными производственными заказами;

- приобретение дополнительного оборудования для целевой сдачи в шеринг при условии полной загрузки собственных киберфизических систем фабрики;

- разделение имеющихся на фабрике киберфизических систем на группы оборудования, задействованного в реализации отличающихся бизнес-моделей (с неизменяемыми бизнес-процессами изготовления массовой продукции и с настраиваемыми при кастомизации продукции бизнес-процессами изготовления индивидуализированных заказов);

- перенос в порядке межфирменной производственной кооперации части заказов на другую фабрику и шеринг ее киберфизических систем за агентское вознаграждение в случае отсутствия у фабрики собственных возможностей (технологических компетенций) или в случае пониженных издержек у бизнес-партнера по конкретным составным частям бизнес-проектов и др.

По данным работы [9], ссылающейся на исследования и оценки Pricewaterhouse Coopers, развивающийся сегодня этап экономики совместного потребления, актуальной для цифровой промышленности и применяемой пока только в сегментах автомобильных перевозок, аренды жилых и офисных помещений, велотранспорта, мультимедиаконтента и библиографической продукции, имеет потенциал роста к 2025 г. в объеме 335 млрд долл., что в 23 раза превосходит показатель объемов рынка шеринговых услуг 2014 г. Усредненные оценки сокращения финансово-временных показателей (затраты на приобретение, простой), возникающих в результате шеринга производственного оборудования в промышленных компаниях, составляют 40-60\%.

Исследования [10], связанные с экономикой шеринга, характеризуют объем российского рынка совместного потребления: 2016 г. - 325 млрд р., 2020 г. 1103 млрд р. с положительной динамикой экспоненциального роста. Примечательно, что на диаграмме классификации отечественных компаний в [10], поддерживающих шеринговые бизнес-модели, сегмент промышленного производства отсутствует как вид реализуемой в настоящее время в РФ экономической 
деятельности в этой сфере, что говорит о только зарождающейся в нашей стране активности высокотехнологичного бизнеса, сконцентрированного на экономике совместного потребления.

4 Трансформация рынка труда в цифровизированной промышленности

По данным работы [11], в ближайшее время трудовые функции около 90\% рабочих мест в странах Евросоюза потребуют от работников уверенного владения цифровыми компетенциями (навыки и знания) для работы в компаниях Индустрии 3.0+ и Индустрии 4.0. Сегодня ими не обладают примерно 40\% населения европейских государств. Наиболее востребованными на рынке труда в ближайшей перспективе в высокотехнологичной промышленности окажутся компетенции специалистов, входящие в группу STEM (Science, Technology, Engineering and Mathematics).

Сравнительные результаты исследования [12] в области оценки уровней производительности труда в различных индустриально развитых странах показывают существенное отставание Российской Федерации по этому показателю: по отношению к Южной Корее на порядок; по отношению к Италии в 4,58 раза; к США в 3,95 раза; к Великобритании в 3,61 раза; к Германии в 3,06 раза. Факторами роста производительности труда, на которых в первоочередном порядке необходимо сконцентрироваться российским кластерам Индустрии $3.0+$ и бизнес-системам Индустрии 4.0, являются материально-техническое оснащение киберфизическими средствами производства, социально-экономическое обеспечение квалифицированными кадрами, организационно-методическое обеспечение систем экономического управления и др. Элементы этого подхода сегодня активно внедряются, в частности, при трансформации существующих хозяйствующих структур Индустрии 3.0 и создании новых компаний в ГК «Росатом».

\section{5 Экономические риски технологической сингулярности промышленности}

При всех очевидных преимуществах (расширение горизонтов, планирование, оперативность формирования отчетности и ее предоставления менеджменту, автоматический синтез логистических цепочек управления, прозрачность контрольноучетной бухгалтерской деятельности и смарт-контрактов, электронный мониторинг рыночных показателей, систематизация информационных потоков компании, кастомизация продукции на основе анализа потребительского опыта и др.), ожидаемых от внедрения цифровых кибертехнологий в практику хозяйствования промышленных объектов, ряд специалистов, в частности [13], отмечает наличие рисков для устойчивого роста результативности бизнеса, связанных с институциональной и инфраструктурной неопределенностями последствий глубокой и оперативной цифровизации промышленности, затрагивающих аспекты ценообразования в цепочках стоимости цифровых продуктов; дематериализации цифровых активов производящих компаний; перераспределения доходов цифрового бизнеса «в направлении потребителя»; создания доминирующих компаний-монополистов с уникальными решениями в области искусственного интеллекта и др.

Прецедентом, когда ожидания от технологической трансформации соответствовали экономической действительности не в полной мере, является компьютеризация бизнеса (изменение устоявшихся способов хозяйствования компаний с заменой, в частности, счета и логарифмических линеек средствами вычислительной техники), так и не приведшая, по мнению Нобелевского лауреата R. M. Solow, к существенно значимому повышению производительности труда. Аналогичные выводы следу- 
И. О. Жаринов. Особенности хозяйствования инновационных бизнес-структур в промышленной экономике совместного потребления

ют из анализа результатов совместных исследований The International Telecommunication Union и McKinsey Global Institute, 2018 г., прогнозирующих, с одной стороны, масштабные внедрения искусственного интеллекта в сферы бизнеса Индустрии 3.0+ и Индустрии 4.0 и прирост за счет этого мирового ВВП к 2030 г. на 1,2\%, и, с другой, - отсроченный экономический эффект, обусловленный издержками технологической сингулярности промышленности и ее весомыми рыночными рисками.

Количественным показателем, интегрально характеризующим положение национальной экономики (конкурентоспособность бизнеса, макроэкономическая стабильность, уровни образования и занятости населения, объем внутреннего рынка и т. д.) в мировом масштабе, является рейтинговая позиция (индекс) государства в The Global Competitiveness Index, ежегодно обновляемом аналитической группой Всемирного экономического форума (Davos), согласно отчету которого в 2019 г. Российская Федерация позиционирована на 43-м месте с индексом 66,7 из 100, основной вклад в который внесла распространенность интернета и мобильной связи в нашей стране. С позиции инновационного развития экономики, учитывающей объемы выполняемой сегодня компаниями Индустрии 3.0 и Индустрии 3.0+ научно-исследовательской деятельности, патентную активность населения и бизнеса, добавленную стоимость продукции и другие показатели, имеющие прямое отношение к промышленным технологиям, предметным рейтингом является Bloomberg innovation index, где, по данным на 2018 г., Российская Федерация позиционирована на фоне санкционного давления на 25-м месте.

\section{6 Заключение}

Обобщенный исследовательский опыт свидетельствует об отсутствии к настоящему времени устоявшихся и общепризнанных теоретикометодологических положений, комплексно характеризующих шеринг как самостоятельно сформировавшийся раздел экономической науки, обладающий своим уникальным терминологическим аппаратом и описаниями причинноследственных связей, закономерностей и явлений, отражающих процессы совместного потребления, приложенные к отношениям в социально-экономических системах.

Зарождающийся сегодня на десятилетия вперед технологический уклад Индустрии 4.0, ориентированный в социально-экономической перспективе на Общество 5.0 и экономику знаний, базируется на цифровизации основных факторов производства, усилении роли данных в генерации цепочек ценности и формировании добавленной стоимости продукции. Следствием инфраструктурных преобразований промышленности и институциональных условий цифровизации экономики станут новые формы хозяйствования экономических субъектов и новые шеринговые бизнес-модели просьюмеризма, обеспечивающие в конечном итоге рост качества жизни населения. В условиях наблюдаемого сегодня относительно одномоментного возникновения фабрик Индустрии 4.0 и их быстрого старта, очевидно, следует ожидать поэтапное прохождение инновационными компаниями всех фаз эволюционных циклов, сформулированных в [8] и Gartner.

\section{Литература}

1. Глазьев С. Ю. Рывок в будущее: Россия в новых технологическом и хозяйственном укладах. Москва: Книжный мир, 2018. 768 с. Текст: непосредственный. 
2. Ештокин С. В. Диффузия высоких технологий оборонно-промышленного комплекса в гражданский сектор экономики: стратегические шаги к импортозамещению // Вопросы инновационной экономики. 2021. Т.11, № 1. С. 257-278. Текст: непосредственный.

3. Краус Н. Н., Краус Е. Н. Какие изменения несет в себе «Индустрия 4.0» для экономики и производства // Формирование рыночных отношений в Украине. 2018. № 9(208). С. 128-135. Текст: непосредственный.

4. Подшивалова М. В., Пылаева И. С. Бизнес-модели фабрик будущего: идентификация и экономико-математическое описание // Вестник Южно-Уральского государственного университета. Серия «Экономика и менеджмент». 2021. Т. 15, № 2. С. 106-114. Текст: непосредственный.

5. Чернов А. В., Чернова В. А. Актуальные вопросы развития экономики шеринга // Инновации и инвестиции. 2020. № 12. С. 40-45. Текст: непосредственный.

6. Кондратьев В. Б. Индустрия 4.0 и глобальные цепочки стоимости // Проблемы теории и практики управления. 2018. № 6. С. 39-48. Текст: непосредственный.

7. Невмывако В. П. Промышленно-технологическая кооперация крупного бизнеса и структур малого и среднего предпринимательства: опыт РФ и зарубежных стран в сфере технологического импортозамещения // Экономика и социум: современные модели развития. 2021. Т. 11, № 2. С. 169-202. Текст: непосредственный.

8. Степнов И. М., Ковальчук Ю. А. Цифровая бизнес-модель: управление технологиями и контроль прибыли // Инновации в менеджменте. 2020. № 3(25). С. 68-78.

9. Блинникова А. В., Данилина О. М., Дашков А. А. Цифровая трансформация и шеринговая экономика // Вестник университета. 2020. № 8. С. 48-56. Текст: непосредственный.

10. Репушевская О. А., Болотнова О. И. Экономика шеринга: причины появления и пути развития в потребительской кооперации // Вестник Российского университета кооперации. 2021. № 2(44). С. 65-69. Текст: непосредственный.

11. Говорова Н. В. Промышленная политика в ЕС // Научно-аналитический вестник института Европы РАН. 2019. № 1(7). С. 108-113. Текст: непосредственный.

12. Костин К. Б., Субоч А. Н. Современные бизнес-модели электронной коммерции // Вопросы инновационной экономики. 2020. Т.10, № 3. С. 1623-1642. Текст: непосредственный.

13. Степнов И. М., Ковальчук Ю. А. Экономические ловушки внедрения искусственного интеллекта // Экономика. Налоги. Право. 2020. № 13(2). С. 92-102. Текст: непосредственный.

Статья поступила в редакцию 30.08.2021; одобрена после рецензирования 29.10.2021; принята к публикации 01.11.2021

\section{SPECIFICS OF MANAGING INNOVATIVE BUSINESS STRUCTURES IN THE INDUSTRIAL SHARING ECONOMY}

Igor O. Zharinov

Dr. Sci. (Engineering), Prof.,

ITMO University

49a Kronverksky Prospect, St. Petersburg 197101, Russia

mpbva@mail.ru

Abstract. Collaborative consumption is an economic model of relationships between business structures and the consumer community, wherein a collective user replace the holding of an asset by its paid rent. The article considers the features of managing innovative busi- 
И. О. Жаринов. Особенности хозяйствования инновационных бизнес-структур в промышленной экономике совместного потребления

ness structures classified as subjects of economic relations - clusters of Industry $3.0+$ and business systems of Industry 4.0, which implement the model of collaborative consumption of industrial assets. We have analyzed the institutional conditions of the sharing economy as a factor in the development of domestic industry and proposed the strategies for the economic growth of business entities related to the sharing of cyber-physical production equipment. The article presents an analysis of the economic risks caused by the technological singularity of the industry associated with the operational digitalization of the production environment and the increased role of artificial intelligence in business processes. We consider the development of innovative business structures for the sharing economy in terms of the transformation of the labour market.

Keywords: sharing economy, Industry 4.0, cyber-physical systems sharing, technological singularity, risks.

\section{For citation}

Zharinov I. O. Specifics of Managing Innovative Business Structures in the Industrial Sharing Economy. Bulletin of Buryat State University. Economy and Management. 2021; 4 : 62-69 (In Russ.).

The article was submitted 30.08.2021; approved after reviewing 29.10.2021; accepted for publication 01.11.2021. 